\title{
PENGARUH DIMENSI KUALITAS LAYANAN TERHADAP KEPUASAN PELANGGAN INDIHOME TRIPLE PLAY
}

\author{
Ichsan Dwi Armanto1 \\ ${ }^{1,2}$ Fakultas Ekonomi dan Bisnis Universitas Udayana, Bali, Indonesia \\ e-mail: ichsan_dwijip@yahoo.com
}

\begin{abstract}
ABSTRAK
Perkembangan teknologi komunikasi di Indonesia saat ini semakin canggih dalam kehidupan masyarakat yang menggunakan dan tidak dapat dihindarkan. Penelitian ini dilakukan di PT. Telkom Indonesia Tbk Witel Denpasar bertujuan untuk mengetahui pengaruh dimensi kualitas layanan terhadap kepuasan pelanggan dengan jumlah sampel sebanyak 90 pelanggan, dengan menggunakan metode non probability sampling. Jenis sampel yang dipilih menggunakan teknik purposive sampling. Pengumpulan data dilakukan melalui kuesioner. Melalui penyebaran kuesioner dengan menggunakan Skala likert untuk mengukur kualitas layanan, kepuasan pelanggan. Skala likert yang digunakan adalah jangkuan nilai 1 sampai dengan 5. Teknik analisis yang digunakan adalah regresi berganda. Berdasarkan hasil analisis ditemukan bahwa dimensi kualitas layanan yang meliputi bukti fisik, keandalan, daya tanggap, jaminan, empati berpengaruh positif dan signifikan terhadap kepuasan pelanggan.
\end{abstract}

Kata kunci: kualitas produk, bukti fisik, keandalan, daya tanggap, jaminan, empati, kepuasan pelanggan

\begin{abstract}
The development of communications technology in Indonesia is now increasingly sophisticated in the lives of people who use and can not be avoided. Increasing number of people who use the internet media. This study was conducted at PT. Telkom Indonesia Witel Denpasar Tbk aims to determine the effect of service quality dimensions on customer satisfaction with the number of samples of 90 customers, using non-probability sampling method. .The sample type wa chosen using purposive sampling technique. The data were collected through questionnaires. Through the distribution of questionnaires likert scale to measure the quality of service, customer satisfaction. Likert scale used is the range of values 1 to 5. The analysis technique used is multiple regression. Based on the analysis result found that service quality dimension which include physical evidence, reliability, responsiveness, assurance, empathy have positive and significant effect to customer satisfaction.
\end{abstract}

Keyword: product quality, physical evidence, reliability, responsiveness, assurance, empathy, customer satisfaction 


\section{PENDAHULUAN}

Perkembangan teknologi komunikasi di Indonesia saat ini semakin canggih dalam kehidupan masyarakat yang menggunakan dan tidak dapat dihindarkan. Bertambahnya banyaknya masyarakat yang menggunakan media internet. Internet pada awalnya merupakan media browsing untuk keperluan militer dengan nama sebelumnya Arpanet (Advanced Research Project Agency Network) yang dibentuk oleh 'Departemen Pertahanan’ Amerika Serikat pada tahun 1969. Namun seiring dengan perkembangan zaman yang semakin maju, kini internet menjadi media komunikasi hampir semua kalangan masyarakat biasa mengakses baik menggunakan Handphone (hp) dan komputer.

PT. Telkom Indonesia Tbk Witel Denpasar sebagai sebuah penyedia jasa pelayanan umum yang mengawasi sektor telekomunikasi di Indonesia berkewajiban untuk selalu meningkatkan bentuk pelayanan kepada pelanggan. Peningkatan pelayanan adalah suatu kata yang sangat diinginkan oleh setiap pelanggan, apapun bentuk bisnisnya tidak terkecuali pada harapan pelanggan di PT. Telkom Indonesia Tbk Witel Denpasar. Perusahaan penyelenggara informasi dan telekomunikasi serta penyedia jasa dan jaringan telekomunikasi secara lengkap (full service and network provider) yang terbesar di Indonesia. Visi dari Telkom yaitu berupaya untuk menempatkan diri sebagai perusahaan InfoComm terkemuka dikawasan Asia Tenggara, Asia dan berlanjut ke kawasan Asia Pasifik. Misi yang dimiliki PT. Telkom Indonesia Tbk Witel Denpasar yaitu memberikan pelayanan dengan jaminan bahwa pelanggan akan mendapatkan layanan terbaik, berupa kemudahan, produk dan jaringan berkualitas, dengan harga kompetitif. PT. 
Telkom Indonesia Tbk Witel Denpasar mengelola bisnis melalui praktek-praktek terbaik dengan mengoptimalisasikan sumber daya manusia yang unggul, penggunaan teknologi yang kompetitif, serta membangun kemitraan yang saling menguntungkan dan saling mendukung secara strategis. Memberikan pelayanan yang baik dan berkualitas kepada pelanggan merupakan salah satu usaha strategi pokok yang dapat digunakan setiap perusahaan untuk mencapai keberhasilan tujuan usaha.

Menurut Kotler (2005:49), kualitas produk adalah keseluruhan ciri serta dari suatu produk atau pelayanan pada kemampuan untuk memuaskan kebutuhan yang dinyatakan atau tersirat. Menurut Lupiyoadi (2001:158) menyatakan bahwa konsumen akan merasa puas bila hasil evaluasi mereka menunjukan bahwa yang mereka gunakan berkualitas.

Chaniotakis dan Lymperopoulos (2009) menyatakan bahwa kualitas pelayanan sebagai sikap konsumen yang berkaitan dengan hasil dari perbandingan antara harapan dari layanan dengan persepsinya terhadap kinerja aktual. Kualitas layanan merupakan segala kegiatan yang bertujuan untuk memenuhi kebutuhan dan keinginan pelanggan agar sesuai harapan mereka (Purbarani, 2013).

Ketatnya persaingan pada saat ini membuat perusahaan dituntut mampu bertahan dan selalu mencoba memberikan pelayanan yang memuaskan agar dapat menarik perhatian dan mempertahankan pelanggannya Vranakis, et al. (2012). Herlistyani (2012) menyatakan bahwa dalam proses pelayanan sendiri terdapat upaya saling memberi dan menerima suatu informasi. Karena apabila telah terjadi timbal balik dan memberikan suatu manfaat yang positif maka hal tersebut akan 
menimbulkan sesuatu yang biasa meningkatkan kepercayaan. Jika pelanggan percaya, berarti dia merasa puas dan kebutuhan yang dia butuhkan dan harapkan telah terpenuhi, sehingga secara otomatis akan muncul loyalitas atau kesetiaan dalam diri pelanggan tersebut.

Tony Wijaya (2011:11) Kualitas pelayanan didefinisikan sebagai keseluruhan gabungan karakteristik yang dihasilkan dari pemasaran rekayasa produksi dan pemeliharaan yang membuat produk dan jasa tersebut dapat digunakan untuk memenuhi harapan pelanggan atau konsumen. Selain itu, Kotler (2013:150) mengemukakan banyak perusahaan secara sistematis mengukur seberapa baik mereka memperlakukan pelanggan mereka mengenali faktor-faktor yang membentuk kepuasan.

Kualitas pelayanan sangat berpengaruh terhadap kepuasan pelanggan. Kotler (2013:150) menyatakan kepuasan pelanggan adalah perasaan senang dan kecewa seseorang yang disebabkan oleh kinerja atau hasil suatu produk yang dirasakan, dibandingkan dengan harapannya. Pakar di bidang pemasaran telah mengembangkan dimensi kualitas pelayanan atau faktor-faktor yang mempengaruhi kualitas pelayanan berdasarkan hasil penelitian dan pengalaman terhadap perusahaan. Kepuasan pelanggan adalah sikap dimana proses akhir yang diterima sesudah mendapatkan sesuatu sesuai dengan harapan (Ueltschy et al., 2007).

Kepuasan pelanggan dapat dirasakan pelanggan setelah pelanggan tersebut menggunakan jasa atau produk yang ditawarkan oleh perusahaan barulah pelanggan akan dapat memberikan tanggapannya tentang produk atau jasa 
tersebut sudah sesuai dengan keinginan ataupun harapan pelanggan. Kepuasan merupakan reaksi emosional jangka pendek pelanggan terhadap kinerja jasa tertentu (Lovelock and Waright, 2007:96). Kepuasan pelanggan ditentukan oleh kualitas produk dan kualitas layanan yang dikehendaki pelanggan sehingga jaminan dari kualitas yang diberikan menjadi prioritas bagi perusahaan (Hidayat, 2009).

PT. Telkom Indonesia Tbk Witel Denpasar merupakan salah satu BUMN yang sahamnya saat ini dimiliki oleh pemegang saham mayoritas Perusahaan adalah Pemerintah Republik Indonesia sebesar 52,6\% sedangkan sisanya dikuasai oleh publik sebesar 47,4\%. Saham Perusahaan diperdagangkan di Bursa Efek Indonesia ("BEI"), New York Stock Exchange ("NYSE”), London Stock Exchange (“LSE”) dan public offering without listing ("POWL") di Jepang. PT. Telkom menyediakan jasa telepon tetap kabel (fixed wire line), jasa telepon tetap nirkabel (fixed wireless), jasa telepon bergerak (mobile service), data/internet serta jasa multimedia lainnya. (Sumber: www.telkom.co.id, diakses 2015).

PT. Telkom Indonesia Tbk Witel Denpasar merupakan perusahaan InfoComm yang memiliki layanan paling lengkap dan jaringan terbesar di Indonesia, saat ini telah memperluas portofolio bisnisnya menjadi Telekomunikasi, Informasi, Media dan Edutainment (TIME). Dengan meningkatkan infrastruktur, memperluas teknologi Next Generation Network $(N G N)$ dan memobilisasi sinergi di seluruh jajaran Telkom Group, PT. Telkom Indonesia Tbk Witel Denpasar dapat mewujudkan dan memberdayakan pelanggan ritel dan korporasi dengan memberikan kualitas, kecepatan, kehandalan dan 
layanan pelanggan yang lebih baik. Visi yang dimiliki oleh Telkom yaitu "To become a leading Telecommunication, Information, Media, Edutainment and Services ("TIMES") player in the region"Misi Menyediakan layanan "more for less" TIMES, Menjadi model pengelolaan korporasi terbaik di Indonesia. (Sumber: www.telkom.co.id, diakses 2016).

PT. Telkom Indonesia Tbk Witel Denpasar sebagai perusahaan pemegang jasa telekomunikasi terbesar di Indonesia mengerahkan sumber daya nya untuk meningkatkan Fixed Broadband ke seluruh wilayah Indonesia. Maka dari itu Telkom mengeluarkan produk yang bernama Indihome. Indihome Triple Play adalah produk layanan fixed broadband akses internet dengan menggunakan teknologi yang mendukung fixed broadband. Teknologi yang digunakan saat ini adalah ADSL (Asymmetric Digital Subscriber Line), MSAN (Multi Services Access Node) dan GPON (Gigabyte-Passive Optical Network). Dari setiap produk Indihome memiliki kelebihannya masing-masing seperti, memberikan layanan komunikasi telepon dengan keuangan biaya yang lebih murah dan memiliki kualitas suara yang jernih. Dengan paket telepon rumah menawarkan gratis telepon 1000 menit lokal ataupun interlokal. Kemudian, layanan internet berkecepatan tinggi menggunakan fiber optik yang memiliki banyak keunggulan. Usee TV adalah Layanan televisi interaktif dan personalized berteknologi internet protocol dilengkapi fitur-fitur unggul seperti TV on Demand, Video on Demand, Pause and rewind, Video Recorder. (Sumber : http://indihome.co.id, diakses 2016). 
Perusahaan Fixed Broadband di Indonesia memiliki 5 produk yang selama ini sudah dikenal masyarakat Indonesia yaitu Indihome Triple Play, Indovision, First Media, Biznet, dan MNC Play. Jumlah pelanggan pada masing - masing perusahaan pada tahun 2016 dapat di lihat pada Tabel 1.

Tabel 1.

Daftar Perusahaan Fixed Broadband di Indonesia tahun 2016

\begin{tabular}{lcc}
\hline \multicolumn{1}{c}{ Perusahaan } & Produk & Jumlah Pelanggan \\
& & \\
\hline PT Telkom Indonesia Tbk Witel & Indihome & 3,73 Juta \\
Denpasar & Indovision & 2,3 Juta \\
PT MNC Sky Vision & First Media & 1,4 Juta \\
PT Link Net & Biznet Network & 90 Ribu \\
PT Supra Primatama Nusantara & MNC Play & 20 Ribu \\
PT MNC Kabel Media Com & &
\end{tabular}

Sumber: data http://techno.okezone.com

Data pada Tabel 1 menunjukkan dari 5 perusahaan fixed broadband yang memiliki pelanggan paling banyak di Indonesia yaitu PT. Telkom Indonesia Tbk Witel Denpasar dengan jumlah pelanggan sebesar 3,73 juta pelanggan kemudian di ikuti oleh Indovision dengan 2,3 juta pelanggan, lalu First Media dengan 1,4 juta, Biznet 90 ribu pelanggan dan MNC Play 20 ribu. 5 perusahaan Fixed Broadband pada tabel 1 yang menjadi pesaing utama PT. Telkom Indonesia Tbk Witel Denpasar dengan produknya adalah Indovision dan First Media yang masing-masing di keluarkan oleh PT MNC Sky Vision dan PT Link Net.

Bukti fisik Indihome memiliki layanan terpadu triple play dengan akses internet kecepatan tinggi sesuai dengan kebutuhan pelanggan, akses fiber optik dikota Denpasar sudah terjangkau. Memberikan paket seperti internet fiber, $\mathrm{t} v$ interaktif dan telepon rumah (3p). Peralatan pendukung Indihome Triple Play router modem Indihome Triple Play menghubungkan input model dari kabel FO luar rumah, output pada modem ini koneksi pada internet. Ip set-top box dapat 
menghubungkan perangkat kabel lan yang berasal dari modem dan output yaitu kabel RCA disambungkan ke tv dan memiliki kualitas kabel yang bagus dalam menghubungkan internet router modem ke Ip set-top box.

Keandalan yang dimiliki Indihome membuat pelanggan merasa nyaman karena internet Indihome memiliki kecepatan internet yang cepat dengan harga terjangkau menjadikan harapan yang tinggi untuk menggunakan produk Indihome.

Indihome Triple Play yang merupakan salah satu produk dari PT. Telkom Indonesia Tbk Witel Denpasar, berhasil menarik pelanggan untuk memakai produk Indihome Triple Play tersebut. Berbagai keunggulan produk yang ditawarkan tentunya tidak terlepas dari berbagai kelemahan yang menyertai setiap produk. Harapan pelanggan mengenai produk dan pelayanan Indihome Triple Play tentunya mengharapkan yang terbaik. Kurangnya kinerja Indihome bahwa kualitas layanan Indihome cukup belum maksimal. Berikut keluhan pelanggan Indihome melalui sosial media :

Tabel 2.

Tabel Jenis Komplain Pelanggan Indihome Triple Play di Kota Denpasar

\begin{tabular}{lc}
\multicolumn{1}{c}{ Jenis Komplain } & $\begin{array}{c}\text { Jumlah } \\
\text { Komplain }\end{array}$ \\
\hline $\begin{array}{l}\text { Gangguan Fiber Optik (gangguan channel tv kabel, internet, dan } \\
\text { telpon rumah). }\end{array}$ & 10 \\
$\begin{array}{l}\text { Kualitas tv kabel yang buruk atau chanel tidak perbarui, dan telfon } \\
\text { yang tiba-tiba sering terputus }\end{array}$ & 6 \\
$\begin{array}{l}\text { Internet yang melambat seiring pemakaian. } \\
\text { Koneksi internet yang terputus secara tiba-tiba terkadang jaringan } \\
\text { tidak memadai }\end{array}$ & 1 \\
\hline
\end{tabular}

Sumber:PT. Telkom Indonesia Tbk Witel Denpasar Bulan Nopember 2016

Berdasarkan Tabel 2 jumlah sampel gangguan Indihome Triple Play mencapai 21 pengaduan gangguan di Kota Denpasar. Laporan 10 Pelanggan mengalami Gangguan Fiber Optik (gangguan channel tv kabel, internet, dan 
telpon rumah), kualitas tv kabel yang buruk atau chanel tidak perbarui, laporan 6 pelanggan telfon yang tiba-tiba sering terputus, laporan 1 pelanggan internet yang melambat seiring pemakaian, laporan 4 pelanggan Koneksi internet yang terputus secara tiba-tiba terkadang jaringan tidak memadai.

Jaminan mampu menumbuhkan kepercayaan pelanggan Indihome ,bertransaksi yang aman akan memudahkan pelanggan mendapatkan fasilitas internet yang memadai dan pelanggan internet Indihome Triple Play di harapkan untuk tidak pernah terlambat dalam membayar tagihan internet Indihome Triple Play. Karena jika terlambat dalam membayar kewajiban tersebut akan di kenakan sanksi berupa denda atau jaringan anda bisa di blokir (terisolir) secara otomatis oleh pihak PT. Telkom Indonesia Tbk Witel Denpasar. Seperti yang telah kita ketahui, PT. Telkom Indonesia Tbk Witel Denpasar telah memberikan batas waktu pembayaran kepada seluruh pelanggan nya agar tagihan Indihome Triple Play di bayar sebelum tanggal 20 setiap bulannya. (Sumber: duta-pulsa.co.id).

Empati, memberikan perhatian khusus terhadap pelanggan perusahaan PT. Telkom Indonesia Tbk Witel Denpasar memahami masalah keluhan Indihome Triple Play para pelanggannya dan bertindak demi kepentingan pelanggan, serta memberikan perhatian personal kepada para pelanggan dan memiliki jam operasi yang nyaman. (Sumber:indotelko.com).

Hasil penelitian oleh Merkusi (2015) menyatakan hanya dimensi reliability yang mempunyai pengaruh negatif signifikan terhadap kepuasan pelanggan tour dan travel di Koper Komunika Indonesia. Sedangkan dimensi lain tidak berpengaruh signifikan terhadap kepuasan pelanggan. Hasil penelitian oleh 
(Molaee et al., 2013) menyatakan bahwa jaminan dan empati tidak memiliki dampak positif dan signifikan terhadap kepuasan pelanggan. Hasil ini menunjukkan kurangnya jaminan responden ke bank dan staf bank. Selanjutnya, hasil penelitian menunjukkan bahwa kepuasan pelanggan adalah mediator hubungan antara respon, bukti fisik, kehandalan, dan kepatuhan terhadap hukum dan loyalitas Islam.

Rumusan masalah dalam penelitian ini adalah Bagaimana Dimensi Kualitas Layanan yang terdiri atas Bukti Fisik, Keandalan, Daya Tanggap, Jaminan, Empati berpengaruh pada Kepuasan Pelanggan di PT. Telkom Indonesia Tbk Witel Denpasar. Berdasarkan rumusan masalah tersebut maka yang menjadi tujuan penelitian ini adalah untuk mengetahui Bukti Fisik, Keandalan, Daya Tanggap, Jaminan, Empati pada Kepuasan Pelanggan di PT. Telkom Indonesia Tbk Witel Denpasar.

Penelitian yang dilakukan oleh Nurmalasari (2016) mengenai kualitas layanan, hasil penelitian tersebut menunjukan kepuasan pelanggan berpengaruh positif dan signifikan. Hasil analisis penelitian yang dilakukan oleh Puspita (2015) menunjukan pengaruh parsial yang signifikan terhadap Bukti Fisik (tangible). Hasil analisis penelitian Prastiwi (2017), Putri (2016), menunjukan secara signifikan terhadap kepuasan pelanggan, maka diperoleh hipotesis sebagai berikut.

$\mathrm{H}_{1}$ : Bukti fisik (Tangible) berpengaruh positif terhadap kepuasan pelanggan.

Penelitian yang dilakukan oleh Rahhal (2015), Selvakumar (2015), Muala (2016) menunjukkan hanya dimensi kehandalan (reliability) yang berpengaruh 
positif signifikan, maka diperoleh hipotesis sebagai berikut.

$\mathrm{H}_{2}$ : Kehandalan (Reliability) berpengaruh positif terhadap kepuasan pelanggan.

Penelitian yang dilakukan oleh Nurmalasari (2016) mengenai kualitas layanan, hasil penelitian tersebut menunjukan kepuasan pelanggan berpengaruh positif dan signifikan. Penelitian yang dilakukan oleh Puspita (2015) menunjukan pengaruh parsial yang signifikan terhadap Bukti Fisik (tangible). Hasil penelitian Prastiwi (2017), Putri (2016), menunjukan secara signifikan terhadap kepuasan pelanggan, maka diperoleh hipotesis sebagai berikut.

$\mathrm{H}_{3}$ : Daya tanggap (Responsiveness) berpengaruh positif terhadap kepuasan pelanggan.

Penelitian yang dilakukan oleh Nurmalasari (2016) mengenai kualitas layanan, hasil peneltian tersebut menunjukan kepuasan pelanggan berpengaruh positif dan signifikan. Penelitian yang dilakukan oleh Puspita (2015) menunjukan pengaruh parsial yang signifikan terhadap Bukti Fisik (tangible). Hasil penelitian Prastiwi (2017), Putri (2016), menunjukan secara signifikan terhadap kepuasan pelanggan, maka diperoleh hipotesis sebagai berikut.

$\mathrm{H}_{4}$ : Jaminan (Assurance) berpengaruh positif terhadap kepuasan pelanggan.

Penelitian yang dilakukan oleh Nurmalasari (2016) mengenai kualitas layanan, hasil peneltian tersebut menunjukan kepuasan pelanggan berpengaruh positif dan signifikan. Penelitian dilakuan oleh Puspita (2015) menunjukan pengaruh parsial yang signifikan terhadap Bukti Fisik (tangible). Hasil penelitian 
Prastiwi (2017), Putri (2016), menunjukan secara signifikan terhadap kepuasan pelanggan, maka diperoleh hipotesis sebagai berikut.

$\mathrm{H}_{5}$ : Empati (Empathy) berpengaruh positif terhadap kepuasan pelanggan.

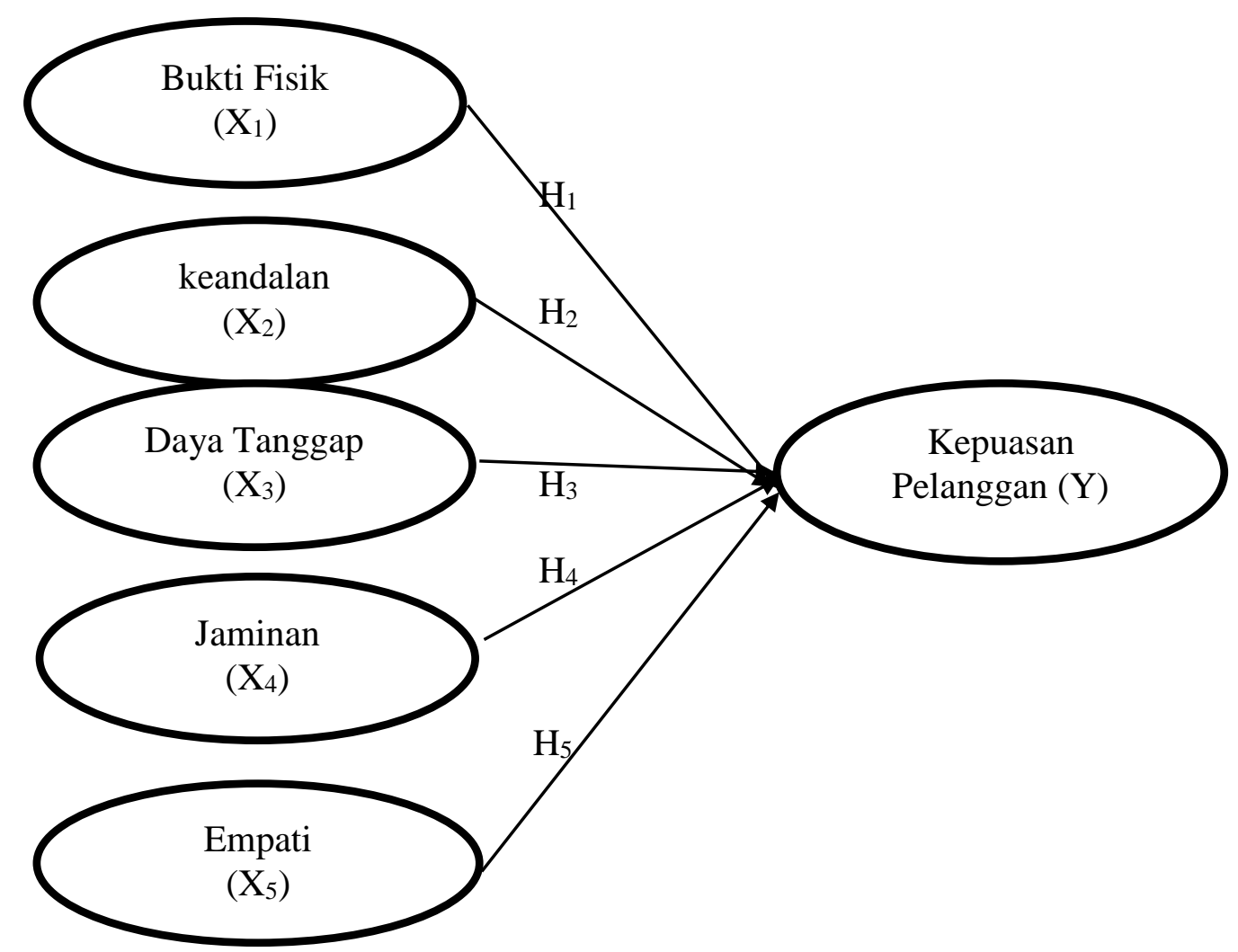

\section{Gambar 1. Model Konseptual Penelitian}

Sumber: Data Diolah, 2017

\section{METODE PENELITIAN}

Berdasarkan tingkat eksplansinya, penelitian ini termasuk dalam jenis penelitian asosiatif. Penelitian asosiatif merupakan penelitian yang bertujan untuk mengetahui hubungan antara dua variabel atau lebih. Penelitian ini bertujuan mengetahui pengaruh variabel bebas (Kualitas layanan) yang meliputi bukti fisik (Tangibles), Keandalan (Reliability), Daya Tanggap (Responsiveness), Jaminan 
(Assurance), Empati (Empathy) dan perbedaan Gender terhadap variabel terikatnya (kepuasan pelanggan).

Penelitian ini dilakukan di sekitar kota Denpasar dengan beberapa alasan, karena pertumbuhan ekonomi di Denpasar cukup tinggi dan didukung dengan daya beli masyarakat yang cukup baik. Kota Denpasar merupakan daerah yang populasi yang penduduk meningkat setiap tahunnya. Selain itu, pelanggan pengguna Indihome Triple Play tersebar diberbagai daerah, khususnya di Kota Denpasar yang menjadi lokasi penelitian.

Adapun yang menjadi Obyek dalam penelitian ini adalah Pengaruh Dimensi Kualitas Layanan Terhadap Kepuasan Pelanggan Indihome Triple Play Studi Pada PT. Telkom Indonesia Tbk Witel Denpasar. Variabel bebas atau Independent Variable dalam penelitian ini terdiri dari Dimensi Kualitas Layanan yaitu, Tangible $\left(\mathrm{X}_{1}\right)$, Reliability $\left(\mathrm{X}_{2}\right)$, Responsiveness $\left(\mathrm{X}_{3}\right)$, Assurance $\left(\mathrm{X}_{4}\right)$, Empathy $\left(\mathrm{X}_{5}\right)$. Variabel atau dependent variable dalam penelitian ini dipengaruhi Karena adanya variable bebas. Variable terikat dalam penelitian ini adalah Kepuasan Pelanggan (Y).

Jenis data dalam penelitian ini terdiri dari data kuantitatif dan data kualitatif. Data kuantitatif adalah data yang berbentuk angka atau bilangan. Sesuai dengan bentuknya, data kuantitatif dapat diolah atau dianalisis menggunakan teknik perhitungan matematika atau statistika. Sedangkan Data kualitatif berfungsi untuk mengetahui kualitas dari sebuah objek yang akan diteliti yang dinilai melalui penilaian responden terhadap pernyataan-pernyataan yang diajukan dalam kuesioner. 
Sumber data dalam penelitian ini meliputi data primer dan data sekunder. Data primer diperlukan untuk mengetahui kepuasan pelanggan yang dapat dilihat dari dimensi kualitas layanan. Untuk mendapatkan data tersebut, akan dibagikan kuesioner kepada para responden. Data sekunder laporan ini yaitu data dalam bentuk jadi yang diperoleh dari literatur atau buku-buku yang berhubungan dengan penelitian ini. Data sekunder dalam penelitian ini berupa bukti, catatan atau laporan historis (berupa laporan penjualan yang berisi omzet penjualan per tahunnya).

Populasi dalam penelitian ini adalah seluruh pelanggan PT. Telkom Indonesia Tbk Witel Denpasar yang menggunakan produk Indihome Triple Play. Pengambilan sampel dalam penelitian ini menggunakan non probability sampling. Non probability sampling merupakan teknik pengambilan sampel bila jumlah besarnya populasi tidak diketahui dan jenis sampling yang dipilih Penelitian ini menggunakan teknik purposive sampling yaitu penentuan sampel dengan pertimbangan tertentu, yaitu anggota dipilih sebagai sampel adalah pelanggan Indihome Triple Play dengan pertimbangan dianggap memahami dan mampu menjawab kuesioner secara obyektif dan pedomannya adalah 5-10 kali jumlah parameter yang diestimasi. Dalam penelitian ini menggunakan 18 indikator dikalikan 5 sehingga banyaknya responden yang diambil sebagai sampel estimasi sebanyak 90 orang.

Metode pengumpulan data yang dipergunakan dalam penelitian ini adalah kuesioner, pengumpulan data dengan menggunakan daftar pertanyaan yang disebarkan kepada responden mengenai pengaruh dimensi kualitas layanan 
terhadap kepuasan pelanggan Indihome Triple Play Studi pada PT. Telkom Indonesia Tbk Witel Denpasar. Sehingga memperoleh data-data yang sesuai dengan penelitian ini.

Uji validitas yaitu menguji valid atau tidaknya instrument penelitian, bila terdapat kesamaan antara data yang terkumpul dengan data yang sesungguhnya terjadi pada objek yang diteliti. Instrumen yang valid berarti alat ukur yang digunakan untuk mendapatkan data (mengukur) itu valid. Ketentuan suatu instrument dikatakan valid atau sahih apabila memiliki koefisien korelasi Pearson Product Moment (r) > 0,3 dengan alpha sebesar 0,05.

Menurut Sugiyono (2013:183) pengujian reliabilitas atau keandalan instrument menunjukkan sejauh mana suatu pengukuran dapat memberikan hasil yang konsisten bila dilakukan pengukuran kembali dengan gejala yang sama. Uji reliablitas dilakukan terhadap instrumen dengan koefisien Cronbach's Alpha lebih besar dari 0,60 maka instrumen yang digunakan reliabel. Untuk menguji reliablititas dilaksanakan dengan bantuan program SPSS 2.0 (Statistic Package of Social Science) for Windows.

Uji Faktor Konfirmatori berfungsi untuk mengestimasi measurement model, menguji unidimensionalitas dari konstruk-konstruk eksogen dan endogen. Model CFA dari masing-masing variabel penelitian yaitu (X) Dimensi Kualitas Layanan, (Y) Kepuasan Pelanggan Korelasi Kaiser Mayer Olkin (KMO) atau barlett's test pada analisis faktor akan menunjukkan validitas konstruk dari analisi faktor. KMO minimal 0,5 dan nilai KMO di bawah 0,5 menunjukkan bahwa analisis faktor tidak dapat digunakan. Faktor pertimbangan apabila eigen value bernilai 
lebih besar dari satu (1) dan varian kumulatifnya minimal 60 persen untuk penelitian-penelitian ilmu social.

Suatu model regresi dikatakan baik bila model regresi linear berganda sudah memenuhi syarat dari uji asumsi klasik yaitu dengan uji normalitas, uji multikolinearitas dan uji heterokedastisitas. Sehingga model regresi perlu dikatakan pengujian asumsi klasik untuk menilai persyaratan-persyratan yang harus dipenuhi agar suatu data mendapatkan hasil yang valid.

Penelitian ini menggukan analisis regresi berganda untuk menganalisis suatu variabel terikat yang dipengaruhi lebih dari satu variabel bebas. Analisis regresi linear berganda ini digunakan untuk tujuan penelitian yaitu menganalisis pengaruh dimensi kualitas layanan terhadap kepuasan pelanggan studi pada "PT. Telkom Indonesia Tbk Witel Denpasar" Digunakan program SPSS dalam menganalisis data. Model regresi berganda ditunjukkan oleh persamaan 1.

$$
Y=\alpha+\beta_{1} X_{1}+\beta_{2} X_{2}+\beta_{3} X_{3}+\beta_{4} X_{4}+\beta_{5} X_{5}
$$

Keterangan :

$\begin{array}{ll}\mathrm{Y} & =\text { Kepuasan Pelanggan } \\ \mathrm{a} & =\text { Konstanta } \\ \beta & =\text { Koefisien Regresi } \\ \mathrm{X}_{1} & =\text { Bukti fisik } \\ \mathrm{X}_{2} & =\text { Kehadanlan } \\ \mathrm{X}_{3} & =\text { Daya tanggap } \\ \mathrm{X}_{4} & =\text { Jaminan } \\ \mathrm{X}_{5} & =\text { Empati } \\ \beta_{1} \beta_{2} \beta_{3} \beta_{4} \beta_{5} & =\text { Koefisien regresi }\end{array}$

HASIL DAN PEMBAHASAN 
Uji validitas yaitu menguji valid atau tidaknya instrument penelitian. Instrumen yang valid berarti alat ukur yang digunakan untuk mendapatkan data (mengukur) itu valid. Instrument yang valid merupakan syarat yang mutlak untuk mendapatkan hasil penelitian yang valid. Ketentuan suatu instrument dikatakan valid atau sah apabila memiliki koefisien korelasi Pearson Product Moment (r) > 0,3 dengan alpha sebesar 0,05 (Sugiyono, 2013:182).

Suatu instrument dikatakan valid jika korelasi antara skor faktor dengan skor total bernilai positif dan nilainya lebih dari $0,30(\mathrm{r}>0,3)$. Tabel 3 menyajikan hasil uji validitas instrumen penelitian. Hasil pengujian terhadap instrumen penelitian berupa uji validitas dan uji reliabilitas disajikan pada Tabel 3 dan 4

Tabel 3.

Hasil Uji Validitas

\begin{tabular}{|c|c|c|c|c|}
\hline Variabel & Dimensi & Indikator & $\begin{array}{l}\text { Koefisien } \\
\text { Korelasi }\end{array}$ & Keterangan \\
\hline \multirow{15}{*}{$\begin{array}{c}\text { Dimensi Kualitas } \\
\text { Layanan (X) }\end{array}$} & \multirow{5}{*}{ Bukti fisik (X1) } & $\mathrm{X}_{1.1}$ & 0.859 & Valid \\
\hline & & $\mathrm{X}_{1.2}$ & 0.843 & Valid \\
\hline & & $\mathrm{X}_{1.3}$ & 0.890 & Valid \\
\hline & & $\mathrm{X}_{2.1}$ & 0.902 & Valid \\
\hline & & $\mathrm{X}_{2.2}$ & 0.908 & Valid \\
\hline & \multirow[t]{2}{*}{ Keandalan (X2) } & $\mathrm{X}_{2.3}$ & 0.834 & Valid \\
\hline & & $\mathrm{X}_{3.1}$ & 0.901 & Valid \\
\hline & \multirow{2}{*}{$\begin{array}{l}\text { Daya Tanggap } \\
\text { (X3) }\end{array}$} & $\mathrm{X}_{3.2}$ & 0.913 & Valid \\
\hline & & $\mathrm{X}_{3.3}$ & 0.930 & Valid \\
\hline & \multirow{5}{*}{ Jaminan (X4) } & $\mathrm{X}_{4.1}$ & 0.891 & Valid \\
\hline & & $\mathrm{X}_{4.2}$ & 0.870 & Valid \\
\hline & & $\mathrm{X}_{4.3}$ & 0.916 & Valid \\
\hline & & $\mathrm{X}_{5.1}$ & 0.908 & Valid \\
\hline & & $\mathrm{X}_{5.2}$ & 0.879 & Valid \\
\hline & Empati (X5) & $X_{5.3}$ & 0.905 & Valid \\
\hline Variabel & Indikator & Koefisien & elasi & Keterangan \\
\hline
\end{tabular}




\begin{tabular}{rrrr}
\hline & $\mathrm{Y}_{1}$ & 0.935 & Valid \\
& $\mathrm{Y}_{2}$ & 0.911 & Valid \\
Kepuasan pelanggan & $\mathrm{Y}_{3}$ & 0.926 & Valid \\
\hline Sumber : Data Diolah, 2017 & &
\end{tabular}

Tabel 3 menunjukkan bahwa hasil uji validitas pada table di atas menunjukkan bahwa seluruh variabel memiliki nilai koefisien korelasi dengan skor total seluruh item pernyataan lebih dari 0,30 , yaitu dari nilai koefisien korelasi terendah sebesar 0,834 hingga nilai koefisien korelasi tertinggi sebesar 0,935. Ini berarti bahwa keseluruhan indikator yang digunakan dinyatakan valid.

Menurut Sugiyono (2013:183) pengujian reliabilitas atau keandalan instrumen menunjukkan sejauh mana suatu pengukuran dapat memberikan hasil yang konsisten bila dilakukan pengukuran kembali dengan gejala yang sama. Suatu instrumen dikatakan reliabel, jika instrumen tersebut memiliki nilai Cronbach's Alpha lebih dari 0,60. Hasil dari uji reliabilitas dapat ditunjukkan pada tabel berikut:

Tabel 4.

Hasil Uji Reliabilitas

\begin{tabular}{lccc}
\hline Variabel & Dimensi & $\begin{array}{l}\text { Cronbach's } \\
\text { Alpha }\end{array}$ & Keterangan \\
\hline & Bukti fisik $\left(\mathrm{X}_{1}\right)$ & 0,828 & Reliabel \\
& Keandalan $\left(\mathrm{X}_{2}\right)$ & 0,854 & Reliabel \\
Dimensi Kualitas Layanan (X) & Daya Tanggap $\left(\mathrm{X}_{3}\right)$ & 0,900 & Reliabel \\
& Jaminan $\left(\mathrm{X}_{4}\right)$ & 0,869 & Reliabel \\
& Empati $\left(\mathrm{X}_{5}\right)$ & 0,870 & Reliabel \\
Kepuasan Pelanggan (Y) & & 0,909 & Reliabel \\
\hline Sumber: Data Diolah, 2017 & & &
\end{tabular}

Hasil uji reliabilitas yang disajikan dalam tabel menunjukkan bahwa seluruh instrumen penelitian memiliki koefisien Cronbach's Alpha lebih dari 0,60. Hal ini 
dapat dikatakan bahwa semua instrumen reliabel sehingga dapat digunakan untuk melakukan penelitian.

Uji ini bertujuan untuk mengetahui apakah residual dari model regresi yang dibuat berdistribusi normal atau tidak. Pengujian normalitas data dilakukan dengan menggunakan uji Kolmogorov Smirnov, apabila koefisien Asymp. Sig. (2tailed) lebih dari 0,05 maka data tersebut dikatakan berdistribusi normal.

Tabel 5.

Hasil Uji Normalitas

\begin{tabular}{lr}
\hline & Unstandardized Residual \\
$\mathrm{N}$ & \\
Kolmogorov-Smirnov Z & 90 \\
Asymp.Sig.(2-tailed) & 1,070 \\
\hline Sumber: Data Diolah, 2017 & 0,202 \\
\hline
\end{tabular}

Berdasarkan Tabel 5 dapat dilihat bahwa nilai Kolmogorov Smirnov (K-S) sebesar 1,070, sedangkan nilai Asymp. Sig. understandardized residual (2-tailed) sebesar 0,202. Hasil tersebut mengindikasikan bahwa model persamaan regresi tersebut berdistribusi normal karena nilai Asymp. Sig. understandardized residual (2-tailed) 0,202 lebih dari nilai alpha 0,05.

Uji ini bertujuan untuk menguji apakah pada model regresi ditemukan adanya korelasi antar variabel bebas. Multikolinearitas dapat dilihat dari nilai tolerance atau variance inflation factor (VIF). Jika nilai tolerance lebih dari $10 \%$ atau VIF kurang dari 10, maka dikatakan tidak ada multikolinearitas.

Tabel 6.

Hasil Uji Multikoliearitas

\begin{tabular}{lcr}
\hline \multicolumn{1}{c}{ Variabel } & Tolerance & VIF \\
\hline Bukti Fisik $\left(\mathrm{X}_{1}\right)$ & 0,680 & 1,471 \\
Keandalan $\left(\mathrm{X}_{2}\right)$ & 0,554 & 1,806 \\
Daya Tanggap $\left(\mathrm{X}_{3}\right)$ & 0,425 & 2,350 \\
Jaminan $\left(\mathrm{X}_{4}\right)$ & 0,539 & 1,854 \\
Empati $\left(\mathrm{X}_{5}\right)$ & 0,425 & 2,355 \\
\hline Sumber: Data Diolah, 2017 & &
\end{tabular}


Berdasarkan Tabel 6 dapat dilihat bahwa nilai tolerance dan VIF dari seluruh variabel menunjukkan bahwa nilai tolerance untuk setiap variabel lebih dari $10 \%$ dan nilai VIF kurang dari 10 yang berarti model persamaan regresi bebas dari multikolinearitas.

Uji ini bertujuan untuk mengetahui apakah dalam model regresi terjadi ketidaksamaan varians dari residual satu pengamatan ke pengamatan lain yang dilakukan dengan uji Glejser. Jika tidak ada satu pun variabel bebas yang berpengaruh signifikan terhadap nilai absolute residual atau nilai signifikansinya di atas 0,05 maka tidak mengandung gejala heteroskedastisitas.

Tabel 7. Hasil Uji Heteroskedastisitas

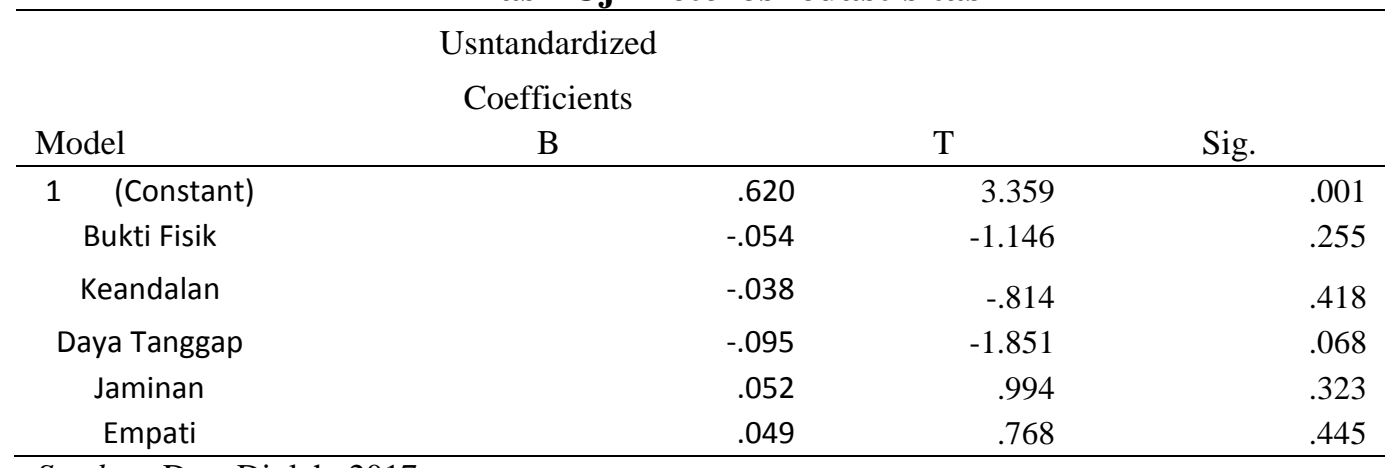

Sumber: Data Diolah, 2017

Pada Tabel 7 dapat dilihat bahwa nilai signifikansi dari variabel bukti fisik sebesar 0,255 lebih dari 0,05, nilai signifikansi dari variabel keandalan sebesar 0,418 lebih dari 0,05 , nilai signifikansi dari variabel daya tanggap sebesar 0,068 , nilai signifikansi dari variabel jaminan sebesar 0,323 , nilai signifikansi dari variable empati sebesar 0,445 yang berarti tidak terdapat pengaruh antara variabel bebas terhadap absolute residual. Dengan demikian, model yang dibuat tidak mengandung gejala heteroskedastisitas. 
Pengujian data dalam penelitian ini menggunakan teknik analisis regresi berganda. Berikut hasil analisis regresi berganda.

Tabel 8.

Hasil Analisis Regresi Berganda

\begin{tabular}{|c|c|c|c|c|c|c|}
\hline $\bar{Y}$ & \multicolumn{6}{|c|}{$0 \mathrm{X}_{2}+0,245 \mathrm{X}_{3}+0,356 \mathrm{X}_{4}+0,264 \mathrm{X}_{5}$} \\
\hline SE & $=0,289$ & 0,073 & 0,074 & 0,008 & 0,083 & 0,100 \\
\hline T Hitung & $=-3,059$ & 2,555 & 2,444 & 3,064 & 4,312 & 2,642 \\
\hline Sig Uji T & $=0,003$ & 0,012 & 0,017 & 0,003 & 0,000 & 0,010 \\
\hline F Hitung & $=57,753$ & & & & & \\
\hline Sig Uji F & $=0$ & & & & & \\
\hline $\mathrm{R}^{2}$ & $=0,755$ & & & & & \\
\hline
\end{tabular}

Sumber: Data Diolah, 2017

Berdasarkan hasil analisis regresi berganda seperti yang disajikan pada Tabel 8, maka persamaan strukturalnya adalah sebagai berikut:

$$
\begin{gathered}
Y=\beta_{1} X_{1}+\beta_{2} X_{2}+\beta_{3} X_{3}+\beta_{4} X_{4}+\beta_{5} X_{5} \\
Y=0,884 X_{1}+0,188 X_{2}+0,245 X_{3}+0,356 X_{4}+0,210 X_{5}
\end{gathered}
$$

Berdasarkan hasil pengujian hipotesis pengaruh bukti fisik terhadap kepuasan pelanggan, diperolah koefisien Beta sebesar 0,160 dengan signifikansi sebesar $0.012<0.05$ yang berarti $\mathrm{H}_{0}$ ditolak dan $\mathrm{H}_{1}$ diterima. Hasil ini menunjukan bahwa bukti fisik berpengaruh secara positif dan signifikan terhadap kepuasan pelanggan. Hal ini menunjukkan bahwa bukti fisik yaitu fasilitas fisik, peralatan, perlengkapan akan meningkatkan kualitas yang diberikan oleh PT. Telkom Indonesia Tbk Witel Denpasar kepada kepuasan pelanggan. Penelitian ini sesuai dengan penelitian yang dilakukan oleh Putri (2013) dalam penelitiannya pada D\&I Skin Centre Hasil penelitian menunjukan secara positif dan pengaruh signifikan antara kualitas pelayanan jasa bukti fisik terhadap kepuasan pelanggan. 
Selanjutnya, dari hasil penelitian yang dilakukan oleh Nurmalasari (2016) diketahui bahwa bukti fisik berpengaruh secara positif dan signifikan terhadap kepuasan pelanggan hotel Zoom.

Berdasarkan hasil pengujian hipotesis pengaruh keandalan terhadap kepuasan pelanggan, diperolah koefisien Beta sebesar 0,170 dengan signifikansi sebesar $0.017<0.05$ yang berarti $\mathrm{H}_{0}$ ditolak dan $\mathrm{H}_{1}$ diterima. Hasil ini menunjukan bahwa keandalan berpengaruh secara positif dan signifikan terhadap kepuasan pelanggan. Hal ini menunjukkan bahwa keandalan yaitu kecepatan layanan, tunjukan minat yang tulus dalam memecahkan pelanggan, Menyediakan layanan pada waktu yang dijanjikan oleh PT. Telkom Indonesia Tbk Witel Denpasar kepada kepuasan pelanggan. Penelitian ini sesuai dengan penelitian yang dilakukan oleh Puspita (2015), dalam penelitiannya pada berbasis web

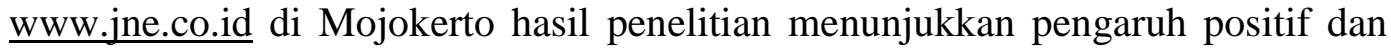
signifikan antara variabel terhadap kepuasan pelanggan.

Berdasarkan hasil pengujian hipotesis pengaruh daya tanggap terhadap kepuasan pelanggan, diperolah koefisien Beta sebesar 0,243 dengan signifikansi sebesar $0.003<0.05$ yang berarti $\mathrm{H}_{\mathrm{o}}$ ditolak dan $\mathrm{H}_{1}$ diterima. Hasil ini menunjukan bahwa daya tanggap berpengaruh secara positif dan signifikan terhadap kepuasan pelanggan. Hal ini menunjukkan bahwa daya tanggap yaitu meliputi respon yang cepat terhadap komplain kepedulian dan keinginan untuk membantu, mudah menanggapi permintaan pelanggan oleh PT. Telkom Indonesia Tbk Witel Denpasar kepada kepuasan pelanggan. Penelitian ini sesuai dengan penelitian yang dilakukan oleh Al-Azzam (2015) dalam penelitiannya pada Bank 
Arab di kota Irbid, Yordania yang menyatakan bahwa daya tanggap berpengaruh positif dan signifikan terhadap kepuasan pelanggan.

Berdasarkan hasil pengujian hipotesis pengaruh jaminan terhadap kepuasan pelanggan, diperolah koefisien Beta sebesar 0,304 dengan signifikansi sebesar $0.000<0.05$ yang berarti $\mathrm{H}_{\mathrm{o}}$ ditolak dan $\mathrm{H}_{1}$ diterima. Hasil ini menunjukan bahwa jaminan berpengaruh secara positif dan signifikan terhadap kepuasan pelanggan. Hal ini menunjukkan bahwa jaminan dalam Keamanan untuk bertransaksi, pelanggan merasa aman dalam bertransaksi memiliki pengetahuan untuk menjawab pertanyaan pelanggan oleh PT. Telkom Indonesia Tbk Witel Denpasar kepada kepuasan pelanggan. Penelitian ini sesuai dengan penelitian yang dilakukan oleh Mahendra (2014) dalam penelitiannya pada kepuasan pelanggan Restoran Baruna Sanur yang menyatakan bahwa empati berpengaruh positif dan signifikan terhadap kepuasan pelanggan.

Berdasarkan hasil pengujian hipotesis pengaruh empati terhadap kepuasan pelanggan, diperolah koefisien Beta sebesar 0,210 dengan signifikansi sebesar $0.010<0.05$ yang berarti $\mathrm{H}_{\mathrm{o}}$ ditolak dan $\mathrm{H}_{1}$ diterima. Hasil ini menunjukan bahwa empat berpengaruh secara positif dan signifikan terhadap kepuasan pelanggan. Hal ini menunjukkan bahwa empati dalam peduli, perhatian Perusahaan, Karyawan memahami kebutuhan pelanggan, oleh PT. Telkom Indonesia Tbk Witel Denpasar kepada kepuasan pelanggan. Penelitian ini sesuai dengan penelitian yang dilakukan oleh Utami (2015) dalam penelitiannya pada kepuasan pelanggan Hotel Griya Sunset Kuta yang menyatakan bahwa jaminan berpengaruh positif dan signifikan terhadap kepuasan pelanggan. Yasa (2014) dalam 
penelitiannya pada Jasa Warnet Nadi Putra Di Denpasar Barat juga menyatakan bahwa Empati berpengaruh positif dan signifikan terhadap kepuasan pelanggan.

\section{SIMPULAN DAN SARAN}

Berdasarkan hasil penelitian dan pembahasan pada penelitian ini, maka dapat disimpulkan bahwa Bukti Fisik berpengaruh positif terhadap Kepuasan Pelanggan di PT. Telkom Indonesia Tbk Witel Denpasar. Hasil menunjukkan bahwa semakin tinggi dan berkualitas tingkat bukti fisik yang diberikan perusahaan, maka akan semakin tinggi pula tingkat kepuasan pelanggan. Keandalan berpengaruh positif terhadap Kepuasan pelanggan di PT. Telkom Indonesia Tbk Witel Denpasar. Hasil menunjukkan bahwa semakin tinggi dan berkualitas tingkat keandalan yang diberikan perusahaan, maka akan semakin tinggi pula tingkat kepuasan pelanggan. Daya Tanggap berpengaruh positif terhadap Kepuasan Pelanggan di PT. Telkom Indonesia Tbk Witel Denpasar. Hasil menunjukkan bahwa semakin tinggi dan berkualitas tingkat daya tanggap yang diberikan perusahaan, maka akan semakin tinggi pula tingkat kepuasan pelanggan. Jaminan berpengaruh positif terhadap Kepuasan Pelanggan di PT. Telkom Indonesia Tbk Witel Denpasar. Hasil menunjukkan bahwa semakin tinggi dan berkualitas tingkat daya tanggap yang diberikan perusahaan, maka akan semakin tinggi pula tingkat kepuasan pelanggan. Empati berpengaruh positif terhadap Kepuasan Pelanggan di PT. Telkom Indonesia Tbk Witel Denpasar. Hasil menunjukkan bahwa semakin tinggi dan berkualitas tingkat empati yang diberikan perusahaan, maka akan semakin tinggi pula tingkat kepuasan pelanggan. 
Bukti fisik, keandalan, daya tanggap, jaminan, empati berpengaruh positif terhadap kepuasan pelanggan di PT. Telkom Indonesia Tbk Witel Denpasar. Hal ini menunjukkan bahwa apabila Bukti fisik, keandalan, daya tanggap, jaminan, empati dijalankan secara efektif dan konsisten maka kepuasan pelanggan akan sangat meningkat.

Berdasarkan pembahasan dan simpulan dalam penelitian ini, adapun saran perbaikan yang dapat disampaikan kepada PT. Telkom Indonesia Tbk Witel Denpasar. Saran yang dapat diberikan kepada PT. Telkom Indonesia Tbk Witel Denpasar untuk meningkatkan bukti fisik, keandalan, daya tanggap, jaminan, empati yang diberikan kepada pelanggan yaitu: meningkatkan akses fiber optik dan kabel untuk menjamin kualitas internet yang lebih baik. Meningkatkan kualitas kecepatan dan harga terkait pada layanan internet Indihome Triple Play. Memberikan pelatihan kepada customer service dan pegawai teknisi dalam bertatap muka dan berinteraksi dengan para pelanggan. Karyawan PT. Telkom Indonesia Tbk Witel Denpasar harus memiliki kemampuan melayani pelanggan dengan tanggap dan cepat. Penelitian ini mempunyai keterbatasan-keterbatasan yang dapat dijadikan bahan pertimbangan bagi peneliti berikutnya agar mendapatkan hasil yang lebih baik lagi, diantaranya: Peneliti menyarankan kepada peneliti selanjutnya agar penelitian yang akan datang mempertimbangkan faktor-faktor lain pada Dimensi Kualitas Layanan yang berhubungan dengan kepuasan pelanggan. 


\section{REFERENSI}

Al-Azzam, Abdel.F.Mahmoud. 2015. The Impact of Service Quality Dimensions on Customers Statisfaction: A Field of Arab Bank in Irbid City, Jordan. European Journal of Business and Management, 7(5), 45-53.

Ayse Ozfer Ozcelik,L. S.A.a.M.S.S. 2007, An Evaluation of Fast- Food Preferences According to Gender. Humanity \& Social Sciences Journal, (2) 43-50.

Boshoff, C., \& G. B. (2004). The Relationships between Service Quality, Customer Satisfaction and Buying Intentions In the Private Hospital Industry. South African Journal of Business Management, 35(4), 2737

Bowen, Jhon T and Shiang-lih Chen. 200. The Relationship Between Customer Loyalty and Customer Satisfaction. International Journal of Contemporary Hospitality Managemet, 3 (13/5) pp 213-217.

Chaniotakis,Ioannis. E. and Constantine Lymperopoulos. 2009. Service Quality Effect on Satisfaction and Word of Mouth in the Health Care Industry. Journal Managing Service Quality, 2 (19), pp: 229 -242.

Eshghi, A., Roy, S. K., \& Ganguli, S. (2008). Service quality and customer satisfaction: An empirical investigation in Indian mobile Telecommunications services. Marketing Management Journal, 18(2), $119-144$.

Herlistyani, Listien, Yunus Winoto \& Asep Saeful Rohman. 2012. Pengaruh Kualitas Jasa Pelayanan Informasi Telkom Terhadap Loyalitas Pelanggan Telkom Speedy Kepada PT. Telekomunikasi Indonesia Tbk. E Jurnal Mahasiswa Universitas Padjajaran,1 (1), 1- 14.

Hidayat, Racmad, 2009. Pengaruh Kualitas Produk dan Nilai Nasabah Terhadap Kepuasan dan Loyalitas Nasabah Bank Mandiri. Jurnal Manajemen dan Kewirausahaan, 11(1): h: 59-72.

Indihome.co.id

Johnson, M.D. \& Gustafsson, A. The evolution and future of nation customer satisfaction index models. Journal of Economic Psychology, 22(2), 217245 .

Lovelock, Christoper H dan Lauren K. Waright. 2007. Manajemen Pemasaran Jasa. Cetakan II. Jakarta: PT. Indeks.

Mahendra, I.Komang. Gede. 2014. Pengaruh Kualitas Layanan Terhadap Kepuasan Konsumen Pada Hotel Griya Sunset Kuta. E-Jurnal Manajemen. Fakultas Ekonomi \& Bisnis Universitas Udayana. 482-499. 
Molaee, Maysam. Ansari, R. \& Teimouri. Analyzing The Impact Of Service Quality Dimensions On Customer Satisfaction And Loyalty In The Banking Of Iran. International Journal Of Academic Reseacrh In Accounting, Finance and Management Sciences, 3 (3), 1-9.

Muala, Al. Ayed. 2016. The Effect of Service Quality Dimensions on Customers' Loyalty through Customer Satisfaction in Jordanian Islamic Bank. International Journal of Marketing Studies, 8 (6), 141-146.

Okezone (2010, agustus 23) 2015, Fixed Broadband Capai 548 Juta Pelanggan. techno.okezone.com/read/2010/08/23/54/365543/2015-fixed broadbandcapai-548-juta-pelanggan.

Novita, Indri dan Nurcahya. 2011. Pengaruh Dimensi Kualitas Pelayanan Jasa Terhadap Kepuasan Pelanggan D\&I Skin Centre Denpasar. Jurnal Manajemen. Fakultas Ekonomi Universitas Udayana, 918-937.

Nurmalasari. Widodo,W. Jokom,R. 2016. Pengaruh Dimensi Kualitas Layanan Terhadap Kepuasan Konsumen Di Hotel Zoo Surabaya. Jurnal Manajemen Perhotelan, Fakultas Ekonomi Universitas Kristen Petra Surabaya Indonesia, 495-507.

Parasuraman, A., Zeithaml, V. A. and Berry, L. L. (1985). A conceptual model of service quality and its implications for future research. Journal of Marketing, 49 (4): 41-50.

Puspita, Indah .Vidya. 2015. Pengaruh Dimensi Kualitas Layanan Berbasis Web Terhadap Kepuasan Pelanggan PT. Jalur Nugraha Ekakurir Kota Mojokerto (Studi Pada JNE). Jurnal Ilmu Administrasi Bisnis Unbraw Malang. 27 (2), 1-7.

Putri, K.I.N.S dan Nurcaya, I. Nyoman. 2013. Pengaruh Dimensi Kualitas Pelayanan Terhadap Kepuasan Pelanggan D\&I SKIN CENTRE DENPASAR. Jurnal Fakultas Ekonomi \& Bisnis Universitas Udayana, 918-937.

Purbarani, V. Hanesty. 2013. Analisis Pengaruh Persepsi Harga, Kualitas Produk, Diferensiasi Produk, Kualitas Layanan Dan Promosi Terhadap Keputusan Pembelian "Studi pada Konsumen Larissa Aesthetic Center Semarang". Diponegoro Journal Of Management, 2 (3), 1-9.

Rahhal, Wael. 2015. The Effects of Service Quality Dimensions on Customer Satisfaction: An Empirical Investigation in Syrian Mobile Telecommunication Services. International Journal of Business and Management Invention, 4 (5), 81-89.

Selvakumar, Joshua. 2015. Impact of Service Quality on Customer Satisfaction in Public Sector and Private Sector Banks, Journal Internasional. 8(1), 1-12. 
Soderlund, M., \& O. N. (2003). Behavioral Intentions in Satisfaction Research Revisited. Journal of Consumer Satisfaction, Dissatisfaction and Complaining Behavior, 16, 53-66.

Sugiyono. 2013. Metode Penelitian Bisnis.Bandung. Alfabeta

Tambunan, R.P. dan Suryawardani.2015. Pengaruh Kualitas Pelayanan Terhadap Kepuasan Pelanggan Pada PT.JNE Perwakilan Kawaluyaan Tahun 2014. Jurnal Bangking and Management Review,4(2), 554-566.

Ueltschy, Linda C., Michael Laroche, Axel Eggert, and Uta Bindl. 2007.Service Quality and Satisfaction: An International Comparison of Professional Service Perceptions. The Journal of Service Marketing, 21(6), 410-423.

Utami, Surya. I. A.I. dan Jatra,I.M. 2015. Pengaruh Kualitas Layanan Terhadap kepuasan Pelanggan Restoran Baruna Sanur. E-Jurnal Manajemen Unud.4(7), 1984-2000.

Vranakis, S., Chatzoglou. P , And Mpaloukas, A. 2012. Customer Satisfaction of Greek Mobile Phone Services. International Journal of Managing Value and Supply Chains, 3(4), pp: 43-54.

Wijaya, Tony. (2011). Manajemen Kualitas Jasa, Edisi Pertama. Indeks, Jakarta

www.duta-pulsa.co.id/sanksi-terlambat-bayar-speedy-indihome/

www.indotelko.com/kanal?c=in\&it=aplikasi-pantau-teknisi-indihome

Yasa, K.A.Saputra. 2014. Pengaruh Kualitas Pelayanan Terhadap Kepuasan Konsumen Pada Jasa Warnet Nadi Putra Di Denpasar. E-Jurnal Manajemen, 1798-1810.

Zaman, R., \& Arslan, M. (2014). Effects of Pre-Announced Product Characteristics on Customer's Purchase Intention. European Journal of Business and Management, 6(23), 167-172. 